Article

\title{
Lidocaine Sensitizes the Cytotoxicity of Cisplatin in Breast Cancer Cells via Up-Regulation of $R A R \beta 2$ and RASSF1A Demethylation
}

\section{Kehan Li ${ }^{1, *}$, Jianxue Yang ${ }^{2}$ and Xuechang Han ${ }^{1}$}

1 Department of Anesthesiology, the First Affiliated Hospital of Henan Science and Technology University, Luoyang 471003, China; E-Mail: hanxuech@163.com

2 Department of Neurology, the First Affiliated Hospital of Henan Science and Technology University, Luoyang 471003, China; E-Mail: jianxyang276@163.com

* Author to whom correspondence should be addressed; E-Mail: khann_li@163.com; Tel./Fax: +86-379-6483-0677.

External Editor: Anthony Lemarié

Received: 19 July 2014; in revised form: 26 November 2014 / Accepted: 3 December 2014 / Published: 17 December 2014

\begin{abstract}
It has been reported that lidocaine is toxic to various types of cells. And a recent study has confirmed that lidocaine exerts a demethylation effect and regulates the proliferation of human breast cancer cell lines. To recognize a potential anti-tumor effect of lidocaine, we evaluated the DNA demethylation by lidocaine in human breast cancer lines, MCF-7 and MDA-MB-231 cells, and determined the influence of demethylation on the toxicity to these cells of cisplatin, which is a commonly utilized anti-tumor agent for breast cancer. Results demonstrated that lidocaine promoted a significant global genomic demethylation, and particularly in the promoters of tumor suppressive genes (TSGs), RAR $\beta 2$ and $R A S S F 1 A$. Further, the lidocaine treatment increased cisplatin-induced apoptosis and enhanced cisplatin-induced cytotoxicity. The combined treatment with both lidocaine and cisplatin promoted a significantly higher level of MCF-7 cell apoptosis than singular lidocaine or cisplatin treatment. Moreover, the abrogation of $R A R \beta 2$ or $R A S S F 1 A$ expression inhibited such apoptosis. In conclusion, the present study confirms the demethylation effect of lidocaine in breast cancer cells, and found that the demethylation of RAR $\beta 2$ and RASSF1A sensitized the cytotoxicity of cisplatin in breast cancer cells.
\end{abstract}


Keywords: lidocaine; DNA demethylation; cisplatin; breast cancer cells; apoptosis

\section{Introduction}

Lidocaine is an aminoamide-type anesthetic, which is commonly used for regional anesthesia and pain relief, due to its rapid onset of action and intermediate efficacy. However, lidocaine occasionally causes neural injury in patients who have received spinal anesthesia using this agent [1,2]. And several studies indicate that lidocaine not only induces neurotoxicity with morphological changes such as cell axon collapse and cell swelling [3,4], but also promotes apoptosis through the mitochondrial pathway [5-9], and even induces necrosis [10-12]. Besides the mitochondrial dysfunction, increased intracellular $\mathrm{Ca}^{2+}, \mathrm{Na}^{+}$, and $\mathrm{pH}$ at least partly contribute to the lidocaine-induced cell apoptosis or necrosis $[13,14]$, such as the toxicity of lidocaine to articular chondrocytes $[15,16]$. However, more detailed molecular mechanisms underlying this cytotoxicity of lidocaine have been little understood.

Studies have indicated that the silencing of tumor suppressor genes (TSGs) through methylation of their promoters is one of the causes of tumor development [17]. As one of the natural covalent modifications of chromatin, defined as epigenomic [18], the silencing of TSGs by DNA methylation induces mechanisms responsible for promoting tumor development such as uncontrolled cell growth, metastasis, and avoidance of apoptosis or maintaining angiogenesis. As an example, methylation of promoter regions of TSGs, such as $C D K N 2 A, V H L$ and $B R C A 1$ render them inactive in cancer cells $[17,19]$. Moreover, DNA methylation may facilitate the mutation of TSGs. In more than $50 \%$ of solid tumors, the tumor suppressive $p 53$ gene is mutated, and $25 \%$ oft he mutations result from methylated cytosine to thymine in the $\mathrm{CpG}$ dinucleotides of this gene [20]. Subsequently, the quantitative analysis of DNA methylation profiles for more cancer-related genes also indicates a strong association of the TSG hypermethylation with colorectal cancers [21] or lung cancers [22].

Several anesthetics have been confirmed to exert demethylation effects and regulate the proliferation of human cancer cells. Procaine promotes DNA demethylation and inhibits the growth of the human breast cancer cell line, MCF-7 [23] and in human hepatoma cells [24]. Recently, lidocaine has also been recognized to promote DNA demethylation in a time- and dose-dependent manner in breast cancer cell lines, BT-20 and MCF-7 in vitro [25]. And this agent has been confirmed to induce endoplasmic reticulum stress-associated apoptosis in a rat pheochromocytoma PC12 cell line [26]. However, it is not clear whether the demethylation effect of lidocaine exerts an anti-tumor effect, and it is not clear whether this anesthetic cooperates with other well-recognized anti-tumor agents, such as cisplatin in the anti-tumor process.

In the present study, we evaluated DNA demethylation by lidocaine in the human breast cancer cell lines MCF-7 and MDA-MB-231, and determined the cooperation of the demethylation-inducing agent with the toxicity of cisplatin, a commonly utilized anti-tumor agent for breast cancer. 


\section{Results}

\subsection{Lidocaine Promotes Global Genomic Demethylation of the CpG Island in Human Breast Cancer Lines}

Two human breast cancer lines, MCF-7 and MDA-MB-231 cells, were treated with various concentrations of lidocaine $(0.01,0.1$ or $1 \mathrm{mM})$ for $72 \mathrm{~h}$ and the global DNA methylation of 5' CpG islands before and after each treatment was measured by sodium bisulfite DNA sequencing. As shown in Figure 1A (column 1 and 2), $10 \mu \mathrm{M}$ 5-aza-2'-deoxycytidine (DAC, a demethylation agent as positive control) treatment significantly reduced the global methylation of the $\mathrm{CpG}$ island in MCF-7 cells, compared to the control MCF-7 cells $(p<0.01)$. The lidocaine treatment with 0.1 or $1 \mathrm{mM}$ also significantly promoted global genomic $\mathrm{CpG}$ island demethylation (Figure 1A, column 4 and 5; both $p<0.05$ ). To confirm the demethylation promotion by lidocaine, MCF-7 cells post $0.1 \mathrm{mM}$ lidocaine for various hours were examined for global genomic methylation. Figure 1B demonstrates that the methylation level was significantly reduced by the $0.1 \mathrm{mM}$ lidocaine treatment for either 72 or $96 \mathrm{~h}$ ( $p<0.05$ for $72 \mathrm{~h}$, and $p<0.01$ for $96 \mathrm{~h}$ ), rather than at $48 \mathrm{~h}$ post treatment.

We then evaluated the global DNA methylation induced by lidocaine in MDA-MB-231 cells. Figure $1 \mathrm{C}$ indicates that the treatment with 0.1 or $1 \mathrm{mM}$ lidocaine for $72 \mathrm{~h}$ also promoted global DNA demethylation ( $p<0.05$ for $0.1 \mathrm{mM}$ and $p<0.01$ for $1 \mathrm{mM}$ ), with a dose-dependence (either $p<0.05$ between the 0.01 and $0.1 \mathrm{mM}$ treatment, or between the 0.01 and $0.1 \mathrm{mM}$ treatment). Moreover, the promotion in MDA-MB-231 cells developed from $48 \mathrm{~h}$ post treatment, earlier than in MCF-7 cells (Figure 1D). The time-dependence of the promotion was also significant $(p<0.01$ or $p<0.001)$, and the demethylation difference between the lidocaine and control groups increased with treatment time. Taken together, lidocaine promotes global genomic demethylation of the $\mathrm{CpG}$ islands in human breast cancer MCF-7 and MDA-MB-231 cells.

Figure 1. Global genomic demethylation of $\mathrm{CpG}$ islands promoted by lidocaine. (A) DNA methylation levels in MCF-7 breast cancer cells treated for $72 \mathrm{~h}$ with $0.01,0.1$ or $1 \mathrm{mM}$ lidocaine treatment, or with $10 \mu \mathrm{M}$ DAC treatment, respectively; (B) DNA methylation levels in MCF-7 cells treated with or without $0.1 \mathrm{mM}$ lidocaine, for 48,72 or $96 \mathrm{~h}$; (C,D) DNA methylation levels in MDA-MB-231 breast cancer cells post above-mentioned treatment respectively. Results were expressed as mean $\pm \mathrm{SD}$ for three independent experiments. Statistical significance was assessed by the unpaired Student's $t$-test $(* p<0.05, * * p<0.01$, or $* * * p<0.001$, ns: no significance).

A

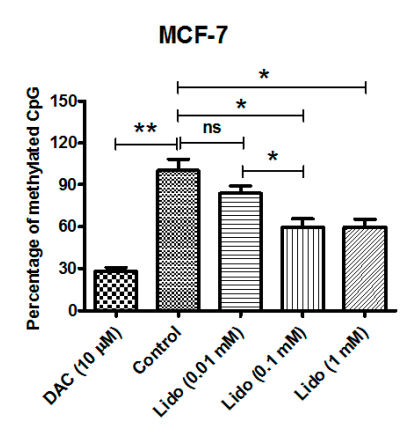

B

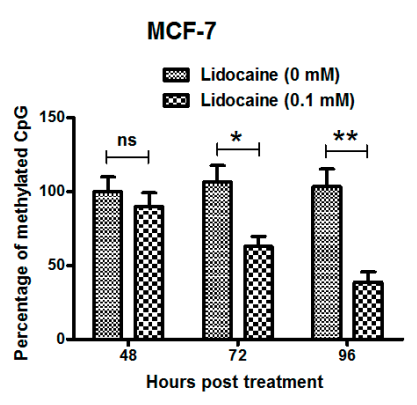


Figure 1. Cont.

C

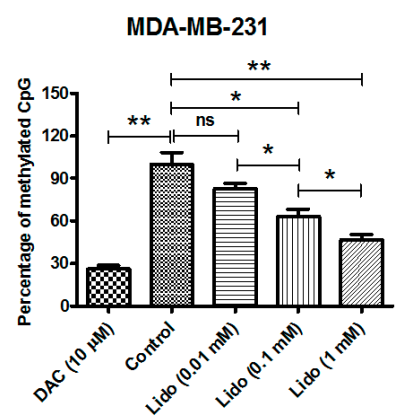

D

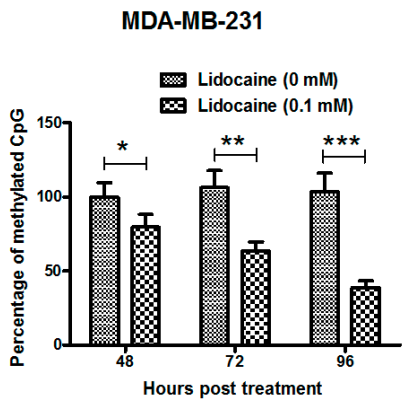

2.2. Lidocaine Ameliorates the Expression of RARB2 and RASSF1A Genes in MCF-7 and MDA-MB-231 Cells

The tumor suppressive genes, Retinoic acid receptor $\beta$ (RARß2) [27] and Ras Association Domain Family 1A (RASSF 1A) [28,29] have been shown to be silenced by their promoter methylation in breast cancers. We evaluated the methylation levels of 5' CpG islands in these two TSG promoters, in MCF-7 cells with lidocaine treatment. Figure 2A,B indicates a similar methylation level in both genes to that of the global genomic $\mathrm{CpG}$ islands in MCF-7 cells; there was a significant dose-dependent demethylation by lidocaine of both $R A R \beta 2$ and $R A S S F 1 A$ genes $(p<0.05$ or $p<0.01$ ). To examine the influence of the promoter demethylation on the expression of $R A R \beta 2$ and $R A S S F 1 A$, we then determined the mRNA and protein levels of both molecules by real-time quantitative PCR (RT-qPCR) and western blot assay. As shown in Figure 2C, there was a significant promotion to $R A R \beta 2$ and RASSF $1 A$ mRNA levels either by $10 \mu \mathrm{M} \mathrm{DAC}$ ( $p<0.01$ respectively), or by $0.1 \mathrm{mM}$ lidocaine treatment for $72 \mathrm{~h}(p<0.05$ respectively). Furthermore, the Western blot assay of both molecules reconfirmed the up-regulation of $R A R \beta 2$ and $R A S S F 1 A$ in protein level by the demethylation, which was promoted by $0.1 \mathrm{mM}$ lidocaine treatment for $96 \mathrm{~h}$ (Figure 2D,E; $p<0.01$ or $p<0.001$ ). Therefore, the demethylation of RAR $\beta 2$ and RASSF1A promotes the expression of both genes.

\subsection{Regulation of Lidocaine on the Viability of MCF-7 and MDA-MB-231 Cells}

$R A R \beta 2$ has been recognized as a potent tumor suppressor. Expression of $R A R \beta 2$ in $R A R \beta 2$-negative cancer cells restored retinoic acid-induced growth inhibition and caused decreased tumorigenicity [30]. Exogenous expression of $R A R \beta 2$ results both in RA-dependent and RA-independent breast cancer cell apoptosis [31,32]. The other TSG, RASSF1A-encoded protein was found to interact with such molecules as CNK1 [33], Nore1 [34], MDM2 [35], MAP1S [36] to induce cell death. Methylation of both TSGs has been reported to silence their expression and promote the tumorigenesis of breast cancers [27-29]. Given the significant demethylation effect of TSGs in breast cancer cells, we supposed a possible anti-tumor effect of lidocaine in the breast cancer cells. Firstly, we examined the viability of both MCF-7 and MDA-MB-231 cells post lidocaine treatment with a range of concentrations. Figure 3A (column 2 compared to column 1, or column 6 compared to column 5) shows that $0.1 \mathrm{mM}$ lidocaine had no impact on the viability of both cell lines, $72 \mathrm{~h}$ post treatment. Also, either 0.01 or $1 \mathrm{mM}$ lidocaine had an impact on cell viability (data not shown). Interestingly, the $0.1 \mathrm{mM}$ lidocaine treatment decreased the cell 
viability reduction which was promoted by $0.2 \mu \mathrm{M}$ cisplatin in both cell lines, $72 \mathrm{~h}$ post treatment (Figure 3A, column 4 or 8 compared to column 3 or 7 ; both $p<0.01$ ). To further determine the deterioration of cell viability induced by lidocaine, we re-evaluated the cell viability post lidocaine treatment, in the presence of $0.2 \mu \mathrm{M}$ cisplatin. The cell viability reduction had been reconfirmed in the dosage of 0.1 or 0.5 rather than $0.02 \mathrm{mM}$ ( $p<0.01$ or $p<0.001$; Figure 3B). Figure 3C,D demonstrated that the cell viability reduction appeared significant from $48 \mathrm{~h}$, and lasted to at least $72 \mathrm{~h}$ post treatment ( $p<0.05$ or $p<0.01$ for MCF-7 cells and $p<0.05$ for MDA-MB-231 cells). Therefore, lidocaine reduced cell viability, in the presence of cisplatin, though its direct regulation was not observed in this study.

Figure 2. Lidocaine-promoted $R A R \beta 2$ and $R A S S F 1 A$ demethylation up-regulates the expression of both genes. Methylation levels of RARß2 (A) or RASSF1A (B) in MCF-7 cells treated for $72 \mathrm{~h}$ with $0.01,0.1$ or $1 \mathrm{mM}$ lidocaine, or with $10 \mu \mathrm{M}$ DAC, respectively; (C) mRNA level of $R A R \beta 2$ or $R A S S F 1 A$ in MCF-7 cells post treatment with $0.1 \mathrm{mM}$ lidocaine or with $10 \mu \mathrm{M}$ DAC for $72 \mathrm{~h}$; Western blot assay for protein level of RARB2 (D) or RASSF1A (E) in MCF-7 cells with or without $0.1 \mathrm{mM}$ lidocaine treatment for $96 \mathrm{~h}$. Each value was expressed as mean $\pm \mathrm{SD}$ for three independent tests. Statistical significance was assessed by the unpaired Student's $t$-test $(* p<0.05, * * p<0.01$, or $* * * p<0.001)$.

A

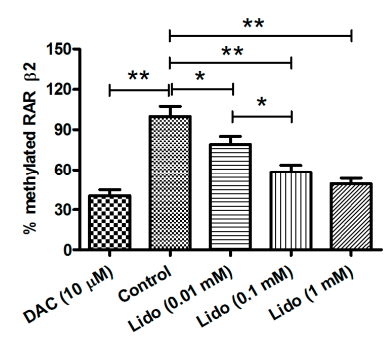

C

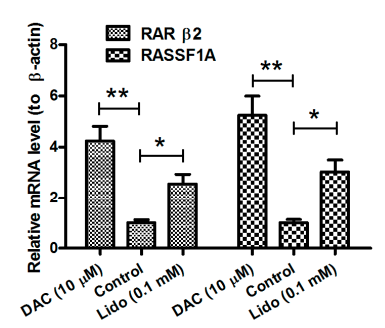

E
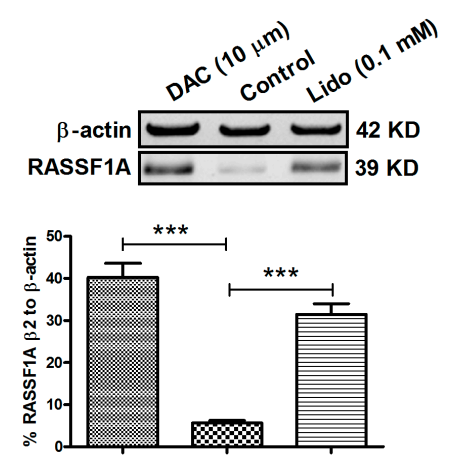

B

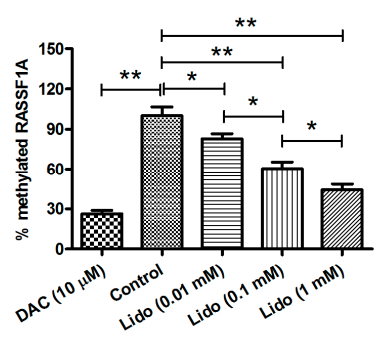

D

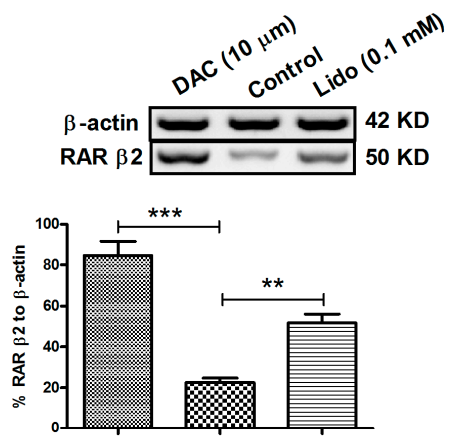


Figure 3. Lidocaine reduces the viability of MCF-7 and MDA-MB-231 cells in the presence of cisplatin. (A) Relative viability of MCF-7 and MDA-MB-231 cells treated with $0.2 \mu \mathrm{M}$ cisplatin or (and) $0.1 \mathrm{mM}$ lidocaine for $72 \mathrm{~h}$; (B) Influence of $0.02,0.1$ or $0.5 \mathrm{mM}$ lidocaine on the viability of $0.2 \mu \mathrm{M}$ cisplatin-treated MCF-7 cells for $72 \mathrm{~h}$; Relative viability of MCF-7 (C) or MDA-MB-231 (D) cells treated with $0.2 \mu \mathrm{M}$ cisplatin or (and) $0.1 \mathrm{mM}$ for 36, 48 or $72 \mathrm{~h}$. All results were averaged for triple independent experiments. And each statistical significance was considered when $p<0.05$ or less. ${ }^{*} p<0.05$, ${ }^{* *} p<0.01$, or $* * * p<0.001$, ns: no significance.

A

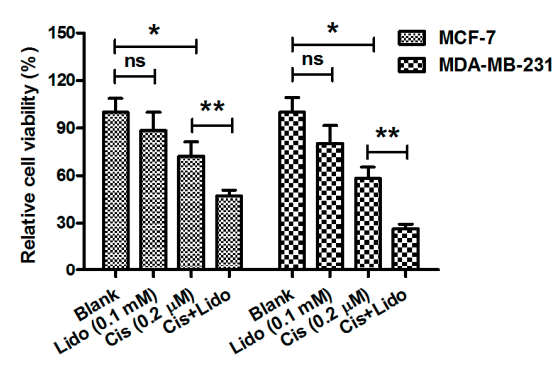

C

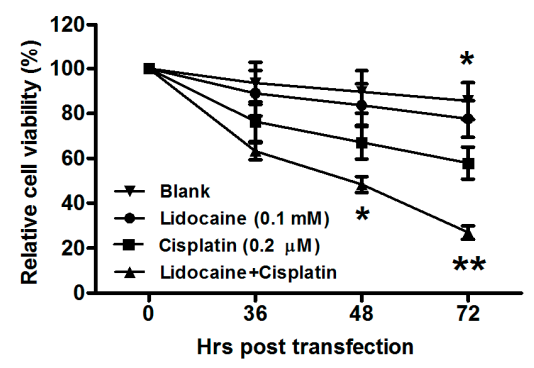

B

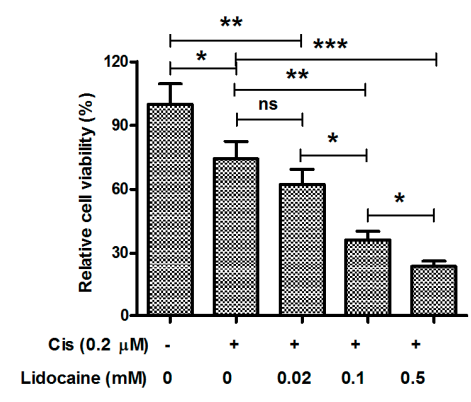

D

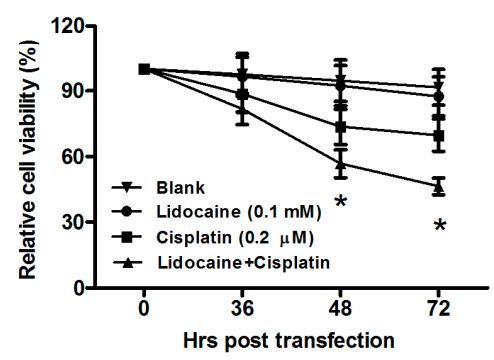

\subsection{Lidocaine Enhances the Cytotoxicity of Cisplatin against MCF-7 Cells}

Cisplatin has been clinically utilized for breast cancer treatment for decades [37,38], and its anti-proliferation effect has been confirmed to be abrogated [39] or sensitized [40] by other molecules. To investigate the regulation of lidocaine on the cisplatin-mediated anti-tumor effect, we evaluated the proliferation of MCF-7 cells, by clone assay, post treatment with $0.1 \mathrm{mM}$ lidocaine, $0.2 \mu \mathrm{M}$ cisplatin, or both agents. It was shown in Figure 4A that MCF-7 cells with or without the above-mentioned treatment formed clones after $96 \mathrm{~h}$ culture at $37{ }^{\circ} \mathrm{C}$, and there was no obvious morphological difference of MCF-7 cells among these groups. Then the clone numbers in each group were calculated, and as shown in Figure 4B, the singular $0.1 \mathrm{mM}$ lidocaine treatment did not significantly regulate clone forming $(p>0.05)$, whereas clone forming of MCF-7 cells was reduced in the presence of $0.2 \mu \mathrm{M}$ cisplatin $(p<0.001)$, and the reduction in clone number was more significant than the singular $0.2 \mu \mathrm{M}$ cisplatin treatment $(p<0.01)$. Taken together, lidocaine inhibits the MCF-7 cell proliferation in the presence of $0.2 \mu \mathrm{M}$ cisplatin, and thus enhances the cytotoxicity of cisplatin against breast cancer cells. 
Figure 4. Colony formation of MCF-7 cells treated with lidocaine and/or cisplatin. (A) Colony formation of MCF-7 cells post the transfection with $0.2 \mu \mathrm{M}$ cisplatin, $0.1 \mathrm{mM}$ lidocaine or with both agents for $96 \mathrm{~h}$; (B) The colony number in groups with or without the treatment of $0.2 \mu \mathrm{M}$ cisplatin and/or $0.1 \mathrm{mM}$ lidocaine. All experiments were performed independently in triplicate. Statistical significance was shown as $* p<0.05, * * p<0.01$, or $* * * p<0.001$, ns: no significance.

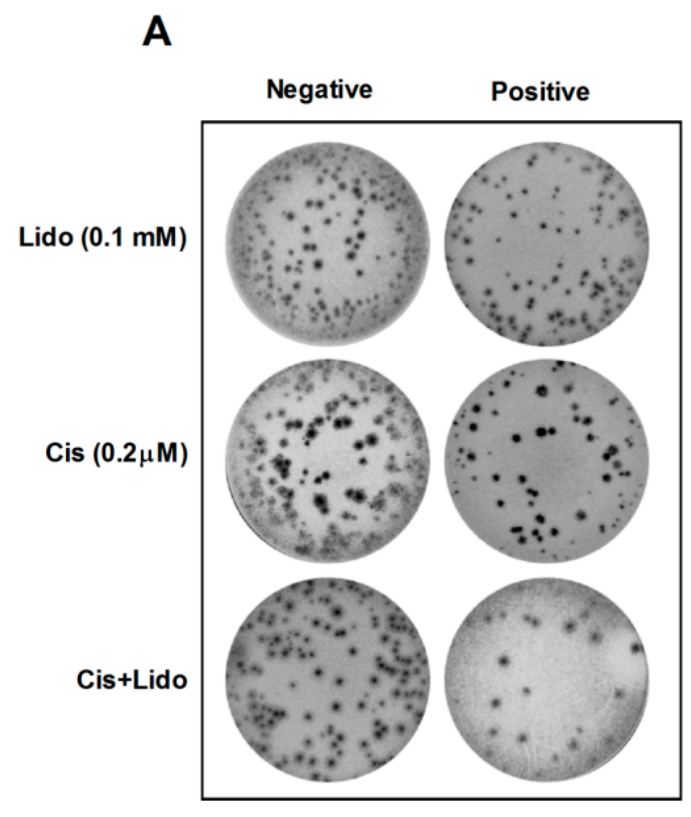

B

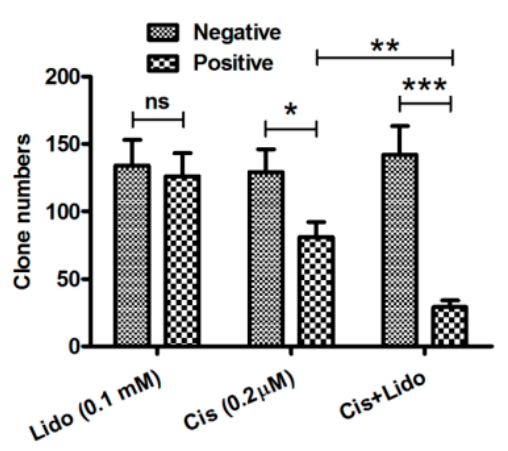

\subsection{Lidocaine Regulation of Apoptosis Promotion by Cisplatin in MCF-7 Cells}

Cisplatin induces apoptosis in breast cancer cells [41,42], and the induction may be suppressed [43] or be sensitized [44]. To confirm whether cisplatin cytotoxicity enhancement by lidocaine is associated with cisplatin-induced apoptosis, we compared apoptosis-induction differences among singular treatment of cisplatin, of lidocaine and the combined treatment with both agents. Firstly, we measured the apoptosis level of MCF-7 cells, post treatment with $0.1 \mathrm{mM}$ lidocaine, with $0.2 \mu \mathrm{M}$ cisplatin, or with both agents, via flow cytometric analysis. It was shown that when subjected to $0.1 \mathrm{mM}$ lidocaine for 36 , 48 or $60 \mathrm{~h}$, less than $10 \% \mathrm{MCF}-7$ cells underwent apoptosis, and there was no significant difference among them (Figure 5A; Figure S1). However, significantly more cells post treatment with $0.2 \mu \mathrm{M}$ cisplatin underwent apoptosis ( $p<0.05$ for $36 \mathrm{~h}, p<0.01$ for 48 or $60 \mathrm{~h}$; Figure 1A). Moreover, $0.1 \mathrm{mM}$ lidocaine sensitized apoptosis promotion by cisplatin; the treatment with both agents promoted 
significantly higher levels of apoptosis in MCF-7 cells ( $p<0.01$ or $p<0.001$ for 36,48 or $60 \mathrm{~h}$, compared to the lidocaine group; and $p<0.05$ for 48 or $60 \mathrm{~h}$, compared to the cisplatin group). Secondly, we analyzed by Western blot analysis apoptosis-associated molecules, such as procaspase 3, which is cleaved in apoptosis and performs as an apoptosis executor, PARPPARP, which is cleaved by activated caspase 3 , and cytochrome $\mathrm{c}$, which is released from mitochondria in apoptosis. Figure 5B-E demonstrates that singular treatment with $0.1 \mathrm{mM}$ lidocaine had no significant regulation on procaspase 3 activation, PARP cleavage and cytochrome c release, all of which were promoted by $0.2 \mu \mathrm{M}$ cisplatin. Moreover, the cisplatin-mediated promotion was sensitized by lidocaine; treatment with both agents promoted higher levels of the activation of above-mentioned molecules than singular cisplatin treatment ( $p<0.01$ or $p<0.001$, compared to the cisplatin group). Finally, we examined the caspase 3 activity with the fluorophore 7-amino-4-methylcoumarin (AMC)-conjuncting kit. Figure 5F confirms the sensitization of lidocaine on the cisplatin-promoted caspase 3 activity; treatment with both agents promoted a significantly higher level of AMC fluorescence intensity than singular lidocaine or cisplatin treatment $(p<0.05$ to $p<0.0001)$. Therefore, lidocaine sensitizes the apoptosis promotion by cisplatin in MCF-7 cells.

\subsection{Abrogation of the RARB2 and RASSF1A Genes Blocks the Apoptosis Promotion by Lidocaine and} Cisplatin in MCF-7 Cells

To further investigate the association of the lidocaine-promoted expression of RAR $\beta 2$ or RASSF 1A with the MCF-7 cell apoptosis, we abrogated the expression of RAR 2 or RASSF1A with the siRNA targeting either gene, and then determine the influence on the MCF-7 cell apoptosis, which was caused by the combined treatment with lidocaine and cisplatin. As shown in Figure 6A,B, the expression of $R A R \beta 2$ or RASSF1A was significantly down-regulated, $48 \mathrm{~h}$ post the siRNA-RAR 2 or SiRNA-RASSF1A transfection, in MCF-7 cells. Moreover, the donw-regulation of the RAR 32 or RASSF $1 A$ expression was also confirmed in in the lidocaine- and cisplatin-treated MCF-7 cells, compared to the siRNA-control (Figure 6C,D; either $p<0.01$ ). We then evaluated the influence of $R A R \beta 2$ or $R A S S F 1 A$ abrogation on the lidocaine- and cisplatin-induced apoptosis of MCF-7 cell cells. Figure $6 \mathrm{E}, \mathrm{F}$ indicated that either siRNA-RAR 32 or siRNA-RASSF $1 A$ transfection significantly inhibited the apoptosis of the MCF-7 cells, subject to $0.1 \mathrm{mM}$ lidocaine and $0.2 \mu \mathrm{M}$ cisplatin, for $48 \mathrm{~h}(p<0.05$ or $p<0.01)$. Therefore, the up-regulated expression of $R A R \beta 2$ or $R A S S F 1 A$ by the lidocaine-mediated demethylation of either gene contributed to the lidocaine- and cisplatin-induced apoptosis. In addition, to exclude a possibly different influence of siRNA transfection on cell apoptosis, we evaluated apoptosis induction of MCF-7 cells post-transfection with siRNA-RASSF1A, siRNA-RAR $\beta 2$, or with siRNA control. No significant difference was found among the three groups (Figure S2). 
Figure 5. Lidocaine enhances cisplatin-induced apoptosis in MCF-7 cells. (A) Apoptotic cells induced by $0.2 \mu \mathrm{M}$ cisplatin, or (and) $0.1 \mathrm{mM}$ lidocaine for 36,48 or $60 \mathrm{~h}$; (B) Western blot analysis of activated caspase 3, cleaved PARP by activated caspase 3 and cytochrome c released from mitochondria in MCF-7 cells treated with $0.2 \mu \mathrm{M}$ cisplatin, and/or $0.1 \mathrm{mM}$ lidocaine for $60 \mathrm{~h}$; (C-E) Relative levels of activated caspase 3, PARP cleavage and cytochrome c release to $\beta$-actin in MCF-7 cells treated with lidocaine, with cisplatin or with both agents; (F) Caspase 3 activity in lidocaine-, cisplatin- or both agents-treated MCF-7 cells, revealing by AMC Caspase Profiling Kit. Each value was averaged for three independent experiment results, and statistical significance was considered when $p<0.05$ or less, $* p<0.05, * * p<0.01, * * * p<0.001, * * * * p<0.0001$, ns: no significance.

A

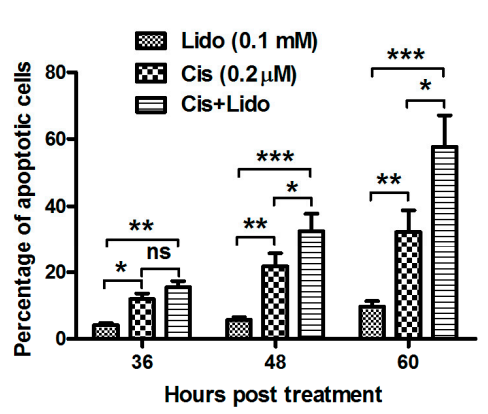

C

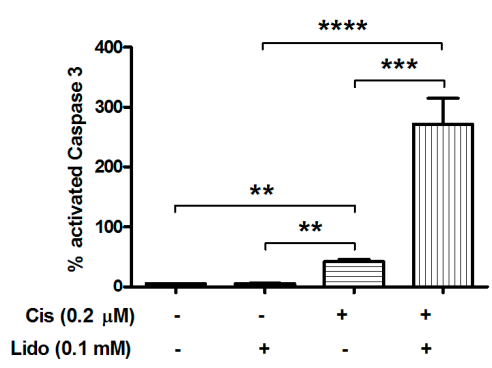

E

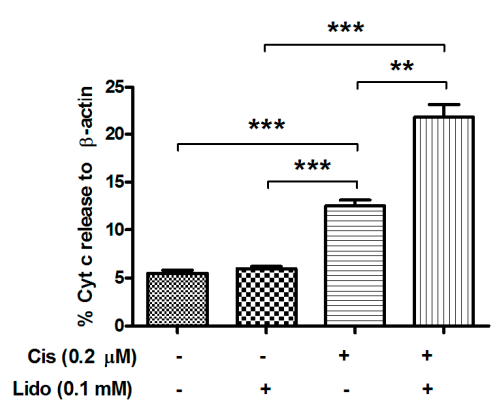

B

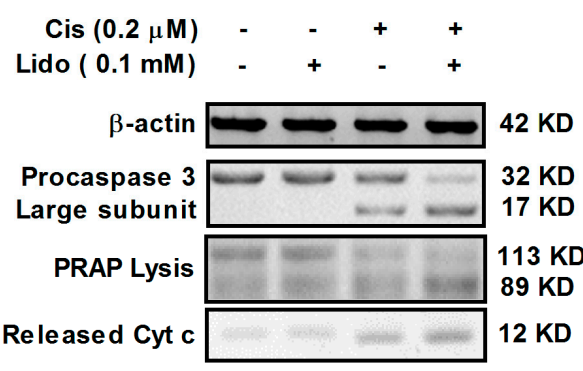

D

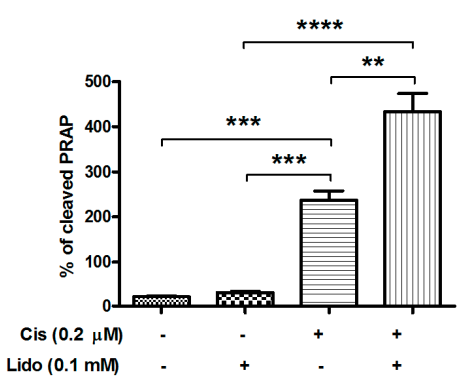

F

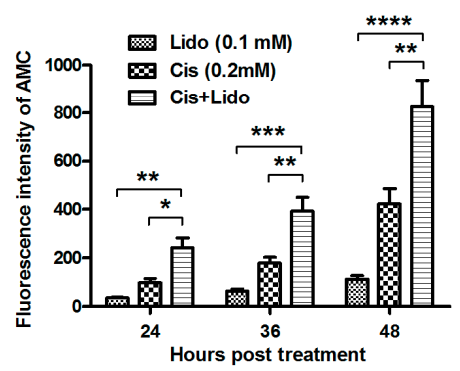


Figure 6. Transfection of $R A R \beta 2$ - or $R A S S F 1 A$-specific siRNA inhibits the lidocaine and cisplatin-induced apoptosis in MCF-7 cells. (A-D) Western blot analysis of $R A R \beta 2$ $(\mathbf{A}, \mathbf{C})$ or RASSF1A $(\mathbf{B}, \mathbf{D})$ expression in MCF-7 cells post-transfection of the RARß2- or $R A S S F 1 A$-specific siRNA, without $(\mathbf{A}, \mathbf{B})$ or with $(\mathbf{C}, \mathbf{D})$ the lidocane and/or cisplatin treatment; $(\mathbf{E}, \mathbf{F})$ Apoptotic cells induced by the combined treatment with $0.1 \mathrm{mM}$ lidocaine and $0.2 \mu \mathrm{M}$ cisplatin for $48 \mathrm{~h}$, post-transfection of RARß2-(E) or RASSF1A-specific siRNA (F) $* p<0.05, * * p<0.01$, ns: no significance.

A

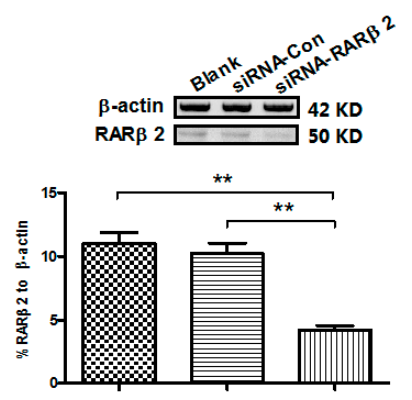

C

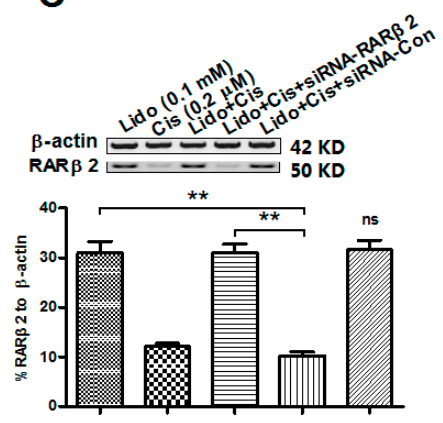

$E$

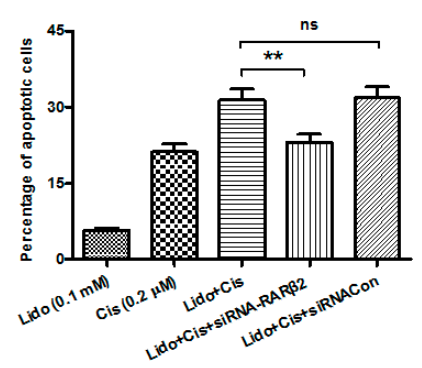

B

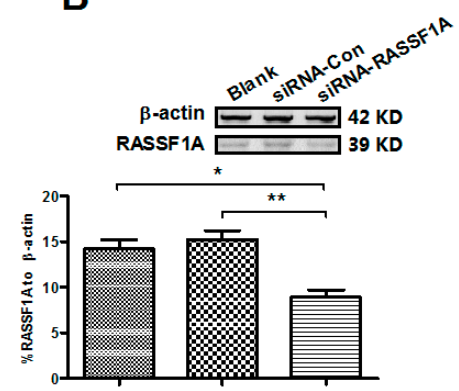

D

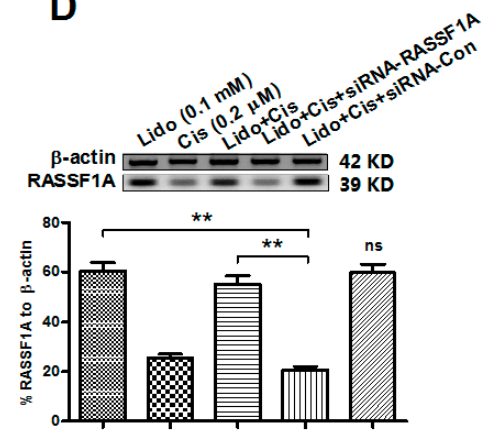

$\mathbf{F}$

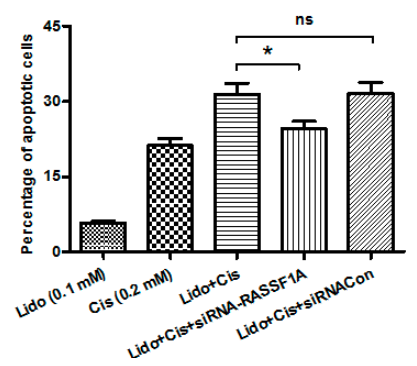

\section{Discussion}

Studies have indicated that silencing of TSGs by promoter methylation contributes to tumor development [17]. TSG silencing by DNA methylation induces mechanisms such as uncontrolled cell growth, metastasis, reduced apoptosis or maintainence of angiogenesis, all of which promote tumor development [17,19]. Moreover, DNA methylation may facilitate the mutation of TSGs, such as mutated p53 [20], or contribute directly to tumorigenesis, such as the hypermethylation in $A P C-1 A, C D K N 2$ and $R A S S F 1 A$ genes in colorectal cancer [21], or the hypermethylation in MTHFR gene in lung cancer [22]. On the other side, promotion of DNA demethylation decreases or inhibits the incidence or the development of cancers [45-48]; DNA demethylation agent 5-aza-2'-deoxycytidine decreases the 
incidence and inhibits the growth of gastric cancers [45,48]; miRNA-34b inhibits prostate cancer through demethylation, activating chromatin modifications [46]; and DNA demethylation by 5-aza-2-deoxycytidine abrogates $17 \beta$-estradiol-induced cell growth of human breast cancer cells [49]. However, the mechanisms of the anti-tumor effects of DNA demethylation agents still need to be clarified.

Lidocaine has recently been indicated to promote DNA demethylation in breast cancer cell lines [25]. The present study has confirmed lidocaine promotion of global genomic demethylation of $\mathrm{CpG}$ islands in MCF-7 and MDA-MB-231 cells; treatment with 0.1 or $1 \mathrm{mM}$ lidocaine for $72 \mathrm{~h}$ promoted global DNA methylation in both cell lines with time-dependent and dose-dependent repeatability. The retinoic acid receptor $\beta(R A R \beta 2)$ was shown to mediate the growth-inhibitory effect of retinoic acid by promoting apoptosis in human breast cancer cells [32] and to be silenced by promoter methylation in breast cancer [27]. RARB2 over-expression restored retinoic acid-induced growth arrest and apoptosis in breast cancer cells [50]. Ras Association Domain Family 1A (RASSF1A), a putative tumor suppressor gene from the 3 p21.3 locus, is another well-recognized tumor suppressive gene in various types of tumors [51-53]. The hypermethylation of CpG Islands in RASSF1A occurs in a large percentage of human breast cancers [54]. Results here indicate that hypermethylation in both genes was reduced significantly by lidocaine treatment, and that the demethylation induced by lidocaine ameliorates the reduced expression of $R A R \beta 2$ and $R A S S F 1 A$, with a significant increase in both mRNA and protein levels in MCF-7 and MDA-MB-231 cells. However, we did not observe significant regulation by lidocaine on viability of either cell line. Interestingly, lidocaine decreased the reduction in cell viability promoted by $0.2 \mu \mathrm{M}$ cisplatin in both cell lines, with time- and dose-dependence. The sensitization effect of lidocaine on the anti-tumor effect of cisplatin was confirmed by clone assay; combined treatment with $0.1 \mathrm{mM}$ lidocaine and $0.2 \mu \mathrm{M}$ cisplatin significantly reduced the clone formation of MCF-7 cells compared to the singular $0.1 \mathrm{mM}$ lidocaine treatment.

Taken together, lidocaine sensitizes the cytotoxicity of cisplatin against breast cancer cells. Cisplatin has been clinically utilized for breast cancer treatment for decades [37,38], and it mainly induces apoptotic death of breast cancer cells $[41,43,55]$. Cisplatin-induced apoptosis has shown to be sensitized by Mdm2 antagonists [56], by the expression of Siva-1 protein [57], or by theophylline [58]. Here, we demonstrate that lidocaine sensitized apoptosis promotion by cisplatin in MCF-7 cells. Though lidocaine did not directly induce apoptosis in MCF-7 cells, it enhanced cisplatin-induced apoptosis; treatments with both agents promoted significantly higher levels of apoptosis in MCF-7 cells. Western blot analysis confirmed sensitization by lidocaine. Treatment with both agents promoted higher expression or activation level of apoptosis-associated molecules, such as activated caspase 3 , cleaved PARP and released cytochrome c. Moreover, apoptosis promotion by lidocaine and cisplatin treatment was inhibited by abrogation of the RAR 32 or $R A S S F 1 A$ gene. Thus, we demonstrate here lidocaine sensitization to the cytotoxicity of cisplatin in MCF-7 breast cancer cells. However, further investigation is needed to clarify the exact mechanisms of sensitization to cisplatin-induced apoptosis in breast cancer cells through lidocaine-induced demethylation of RAR 32 and RASSF $1 A$ genes. 


\section{Materials and Methods}

\subsection{Cell Culture and Treatment with Reagents}

MDA-MB-231 and MCF-7 breast cancer cell lines were provided by the cell resource center of the Chinese Academy of Medical Sciences (Beijing, China). MDA-MB-231 cells were grown in DMEM/F12 (HyClone, Logan, UT, USA), supplemented with 10\% fetal bovine serum (FBS; Gibco, Rockville, MD, USA). MCF-7 breast cells were maintained in Dulbecco's modified Eagle's medium (Invitrogen, Carlsbad, CA, USA), supplemented with 10\% FBS (Gibco, Rockville, MD, USA). Cells were cultured at $37{ }^{\circ} \mathrm{C}$ in $5 \% \mathrm{CO}_{2}$ to $80 \%-90 \%$ confluence and were subjected to DMEM/F12 or DMEM supplemented with $2 \%$ FBS, containing $0.01,0.02,0.1,0.5$ or $1 \mathrm{mM}$ lidocaine (Sigma-Aldrich, St. Louis, MO, USA), $10 \mu \mathrm{M}$ 5-aza-2'-deoxycytidine (DAC) (Sigma-Aldrich) or (and) $0.2 \mu \mathrm{M}$ cisplatin (Sigma-Aldrich for various hours for the DNA methylation sequencing, cell viability or cell apoptosis assay, and cell colony forming assay. DAC or cisplatin was utilized to as a positive demethylation agent or as an apoptosis inducer. To abrogate the expression of $R A R \beta 2$ or RASSF 1A, siRNA-RARß2 (5'-CAGC UGAG UUGG ACGA UCU-3'), siRNA-RASSF1A (5'-GAC CUC UGU GGC GAC UUCA-3') or siRNA control (5'-AGCG AATT AGCT TGCC GTG-3') was synthesized by GenePharma Technology (Shanghai, China) and was transfected by lipofectamine 2000 (Thermo Fisher Scientific, Waltham, MA, USA) with a concentration of $50 \mathrm{nM}$ according to the manufacurer's guidance.

\subsection{Methylation Analysis of Global Genomics and TSGs, RARß2 and RASSF1A}

To analyze the effects of $0.01,0.1$, or $1 \mathrm{mM}$ lidocaine, with $10 \mathrm{mM}$ DAC as positive demethylation agent, we extracted genomic DNA from MDA-MB-231 or MCF-7 cells post various treatment using DNeasy tissue kit (Qiagen, Hilden, Germany) according to the manufacturer' manual. Sodium bisulfite conversion of genomic DNA in each sample was performed as described [59]. The DNA methylation was analyzed using MethyLight method [60], to quantify the methylation level of RAR 32 and RASSF1A, both of which have reported to be hypermethylated in breast cancer $[27,38]$. The methylation status of individual $\mathrm{CpG}$ sites in each gene within the promoter region was determined by the sodium bisulfite-sequencing assay as described previously [61,62].

\subsection{RNA Extraction and RT-qPCR}

Total cellular mRNA samples were extracted from cultured cells using the RNeasy Mini Kit (Qiagen, Valencia, CA, USA). Quantification of RAR 32 and RASSF1A expression was conducted using the QuantiTect SYBR Green PCR Kit (Qiagen, Hilden, Germany) in the LightCycle 2.0 (Roche, Mannheim, Germany). The sequences of the primers for $R A R \beta 2$ are as following, forward primer: 5'-TGAG TCCT GGGC AAAT CCTG-3', reverse primer: 5'-TTGA GAGC TTTC TCCT GGAG-3'. And the sequences of the primers for RASSF $1 A$ are as following, forward primer: 5'-AGCC TGAG CTCA TTGA GCTG-3', reverse primer: 5'-ACCA GCTG CCGT GTGG-3'. All mRNA expression levels were normalized to $\beta$-actin (forward primer: 5'-GATG AGAT TGGC ATGG CTTT-3', revserse primer: 5'-GTCA CCTT CACC GTTC CAGT-3'), and ${ }^{{ }^{\Delta}} C_{\mathrm{t}}$ method was used for relative quantification [63]. 


\subsection{Protein Isolation and Western Blot Analysis}

Total cellular protein samples were prepared with a cell lysis reagent (Sigma-Aldrich) according to the manual and supplemented with a protease inhibitor cocktail (Pierce, Rockford, IL, USA). For the Cyt $\mathrm{C}$ release assay, the cytoplasmic protein was isolated by the Mitochondria/Cytosol Fractionation Kit (Abcam, Cambridge, UK). Each protein sample was separated by 10\% SDS-PAGE gel and was transferred to a nitrocellulose membrane. Then the rabbit polyclonal antibody to RAR $\beta 2$ (Santa Cruz Biotechnology, Santa Cruz, CA, USA), RASSF1A (Abcam, Cambridge, UK), caspase 3 (Sino Biological, Beijing, China), cleaved-PARP (Cell Signaling Technology Inc., Danvers, MA, USA), Cytochrome c (Santa Cruz Biotechnology, Santa Cruz, CA, USA) or $\beta$-actin (Sino Biological, Beijing, China) was used to detect the protein level of each molecule. Goat anti-rabbit IgG conjugated to horseradish peroxidase (Pierce) and ECL detection systems (Super Signal West Femto; Pierce) were used for detection.

\subsection{MTT Assay and Cell Colony Formation Assay}

Cell viability was determined by MTT cell viability assay kit (Biotium Inc., Beijing, China). MCF-7 or MDA-MB-231 cells were seeded in 96-well plates and were incubated at $37{ }^{\circ} \mathrm{C}$ for $24 \mathrm{~h}$ to approximately $85 \%$ confluence, and then cells were treated with $0.1 \mathrm{mM}$ lidocaine, $0.2 \mu \mathrm{M}$ cisplatin or with both agents for various hours. Then cells were incubated with $10 \mu \mathrm{L}$ MTT and were incubated at $37^{\circ} \mathrm{C}$ for $4 \mathrm{~h}$. Post addition of $200 \mu \mathrm{L}$ DMSO into each well to dissolve the formazan, the absorbance was measured on an ELISA plate reader with a test wavelength of $570 \mathrm{~nm}$ and a reference wavelength of $630 \mathrm{~nm}$ to obtain sample signal (OD $\left.570-\mathrm{OD}_{630}\right)$. For cell colony formation assay, $4 \times 10^{2}$ cells were incubated in 6-well plates at $37{ }^{\circ} \mathrm{C}$ containing $5 \% \mathrm{CO}_{2}$, and were treated with $0.1 \mathrm{mM}$ lidocaine, $0.2 \mu \mathrm{M}$ cisplatin or with both agents. $96 \mathrm{~h}$ post treatment, cells were stained with crystal violet $(0.005 \%)$ for 30 min and colony numbers were counted.

\subsection{Cell Apoptosis Assay and Fluorometric Analysis of Caspase 3 Activity}

Apoptosis of MCF-7 or MDA-MB-231 cells was examined with an annexin V/FITC apoptosis detection kit (Abcam, Cambridge, UK). Briefly, approximate $6 \times 10^{5}$ cells post treatment were stained with annexin V-FITC and propidium iodide and detected by a FACScan flow cytometer (BD Biosciences, San Jose, CA, USA). The apoptosis was evaluated by a percentage of apoptotic cells to total cells. The caspase 3 activity was examined with an AMC Caspase Profiling Kit (for caspase 3) (AnaSpec, Fremont, CA, USA) according to the manual. MCF-7 cells (105 cells) post treatment were collected, and the cell pellets were washed with phosphate-buffered saline, then caspase-3-like activity was determined by assessment of Asp-Glu-Val-Asp (DEVD)-AMC cleavage. Briefly, pellets were transferred to a microtiter plate and were resuspended in $100 \mu \mathrm{L}$ (final volume) of a caspase buffer solution supplemented with the fluorogenic peptide substrate Ac-DEVD-AMC. The cleavage was monitored over a $30 \mathrm{~min}$ period at $37{ }^{\circ} \mathrm{C}$ in a Fluoroscan II plate reader using an excitation wavelength of $390 \mathrm{~nm}$ and an emission wavelength of $460 \mathrm{~nm}$. And the activity was expressed as a relative value of fluorescence intensity of AMC to control. 


\section{Conclusions}

In conclusion, we have confirmed the DNA demethylation effects of lidocaine in breast cancer cells, and demonstrated the lidocaine-sensitized cytotoxicity of cisplatin against MCF-7 cells via enhancement of cisplatin-induced apoptosis.

\section{Supplementary Information}

The supplementary figures can be found at http://www.mdpi.com/1422-0067/15/12/23519/s1.

\section{Acknowledgments}

The present study was supported by a grant from The First Affiliated Hospital of Henan Science and Technology University (S2012004).

\section{Author Contributions}

Kehan Li and Jianxue Yang designed the study; Kehan Li, Jianxue Yang and Xuechang Han performed the experiments; Kehan Li and Xuechang Han wrote the paper.

\section{Conflicts of Interest}

The authors declare no conflict of interest.

\section{References}

1. Lambert, L.A.; Lambert, D.H.; Strichartz, G.R. Irreversible conduction block in isolated nerve by high concentrations of local anesthetics. Anesthesiology 1994, 80, 1082-1093.

2. Rigler, M.L.; Drasner, K.; Krejcie, T.C.; Yelich, S.J.; Scholnick, F.T.; DeFontes, J.; Bohner, D. Cauda equina syndrome after continuous spinal anesthesia. Anesth. Analg. 1991, 72, 275-281.

3. Kasaba, T.; Onizuka, S.; Takasaki, M. Procaine and mepivacaine have less toxicity in vitro than other clinically used local anesthetics. Anesth. Analg. 2003, 97, 85-90.

4. Onizuka, S.; Takasaki, M.; Syed, N.I. Long-term exposure to local but not inhalation anesthetics affects neurite regeneration and synapse formation between identified lymnaea neurons. Anesthesiology 2005, 102, 353-363.

5. Werdehausen, R.; Braun, S.; Essmann, F.; Schulze-Osthoff, K.; Walczak, H.; Lipfert, P.; Stevens, M.F. Lidocaine induces apoptosis via the mitochondrial pathway independently of death receptor signaling. Anesthesiology 2007, 107, 136-143.

6. Johnson, M.E.; Uhl, C.B.; Spittler, K.H.; Wang, H.; Gores, G.J. Mitochondrial injury and caspase activation by the local anesthetic lidocaine. Anesthesiology 2004, 101, 1184-1194.

7. Onizuka, S.; Tamura, R.; Hosokawa, N.; Kawasaki, Y.; Tsuneyoshi, I. Local anesthetics depolarize mitochondrial membrane potential by intracellular alkalization in rat dorsal root ganglion neurons. Anesth. Analg. 2010, 111, 775-783. 
8. Onizuka, S.; Yonaha, T.; Tamura, R.; Kasiwada, M.; Shirasaka, T.; Tsuneyoshi, I. Lidocaine depolarizes the mitochondrial membrane potential by intracellular alkalization in rat dorsal root ganglion neurons. J. Anesth. 2011, 25, 229-239.

9. Chang, Y.C.; Liu, C.L.; Chen, M.J.; Hsu, Y.W.; Chen, S.N.; Lin, C.H.; Chen, C.M.; Yang, F.M.; $\mathrm{Hu}$, M.C. Local anesthetics induce apoptosis in human breast tumor cells. Anesth. Analg. 2014, 118, $116-124$.

10. Yagiela, J.A.; Benoit, P.W.; Fort, N.F. Mechanism of epinephrine enhancement of lidocaine-induced skeletal muscle necrosis. J. Dent. Res. 1982, 61, 686-690.

11. Lawrence, V.S.; Marte, E.; Brown, B.W.; van Bergen, F.H. Lidocaine, 2-chlorprocaine and hepatic necrosis. Anesth. Analg. 1966, 45, 55-58.

12. Onizuka, S.; Tamura, R.; Yonaha, T.; Oda, N.; Kawasaki, Y.; Shirasaka, T.; Shiraishi, S.; Tsuneyoshi, I. Clinical dose of lidocaine destroys the cell membrane and induces both necrosis and apoptosis in an identified Lymnaea neuron. J. Anesth. 2012, 26, 54-61.

13. Arrebola, F.; Zabiti, S.; Canizares, F.J.; Cubero, M.A.; Crespo, P.V.; Fernandez-Segura, E. Changes in intracellular sodium, chlorine, and potassium concentrations in staurosporine-induced apoptosis. J. Cell Physiol. 2005, 204, 500-507.

14. Belaud-Rotureau, M.A.; Leducq, N.; Macouillard, P.D.G.F.; Diolez, P.; Lacoste, L.; Lacombe, F.; Bernard, P.; Belloc, F. Early transitory rise in intracellular $\mathrm{pH}$ leads to Bax conformation change during ceramide-induced apoptosis. Apoptosis 2000, 5, 551-560.

15. Karpie, J.C.; Chu, C.R. Lidocaine exhibits dose- and time-dependent cytotoxic effects on bovine articular chondrocytes in vitro. Am. J. Sports Med. 2007, 35, 1621-1627.

16. Rademaker, A.W.; Kellen, J.; Tam, Y.K.; Wyse, D.G. Character of adverse effects of prophylactic lidocaine in the coronary care unit. Clin. Pharmacol. Ther. 1986, 40, 71-80.

17. Lewandowska, J.; Bartoszek, A. DNA methylation in cancer development, diagnosis and therapy-Multiple opportunities for genotoxic agents to act as methylome disruptors or remediators. Mutagenesis 2011, 26, 475-487.

18. Kubicek, S.; Schotta, G.; Lachner, M.; Sengupta, R.; Kohlmaier, A.; Perez-Burgos, L.; Linderson, Y.; Martens, J.H.; O’Sullivan, R.J.; Fodor, B.D. et al. The role of histone modifications in epigenetic transitions during normal and perturbed development. Ernst Scher. Res. Found. Workshop 2006, 57, $1-27$.

19. Ushijima, T. Detection and interpretation of altered methylation patterns in cancer cells. Nat. Rev. Cancer 2005, 5, 223-231.

20. Singal, R.; Ginder, G.D. DNA methylation. Blood 1999, 93, 4059-4070.

21. Van Engeland, M.; Weijenberg, M.P.; Roemen, G.M.; Brink, M.; de Bruine, A.P.; Goldbohm, R.A.; van den Brandt, P.A.; Baylin, S.B.; de Goeij, A.F.; Herman, J.G. Effects of dietary folate and alcohol intake on promoter methylation in sporadic colorectal cancer: The Netherlands cohort study on diet and cancer. Cancer Res. 2003, 63, 3133-3137.

22. Vaissiere, T.; Hung, R.J.; Zaridze, D.; Moukeria, A.; Cuenin, C.; Fasolo, V.; Ferro, G.; Paliwal, A.; Hainaut, P.; Brennan, P. Quantitative analysis of DNA methylation profiles in lung cancer identifies aberrant DNA methylation of specific genes and its association with gender and cancer risk factors. Cancer Res. 2009, 69, 243-252. 
23. Villar-Garea, A.; Fraga, M.F.; Espada, J.; Esteller, M. Procaine is a DNA-demethylating agent with growth-inhibitory effects in human cancer cells. Cancer Res. 2003, 63, 4984-4989.

24. Tada, M.; Imazeki, F.; Fukai, K.; Sakamoto, A.; Arai, M.; Mikata, R.; Tokuhisa, T.; Yokosuka, O. Procaine inhibits the proliferation and DNA methylation in human hepatoma cells. Hepatol. Int. 2007, 1, 355-364.

25. Lirk, P.; Berger, R.; Hollmann, M.W.; Fiegl, H. Lidocaine time- and dose-dependently demethylates deoxyribonucleic acid in breast cancer cell lines in vitro. Br. J. Anaesth. 2012, 109, 200-207.

26. Hong, D.Y.; Kwon, K.; Lee, K.R.; Choi, Y.J.; Goo, T.W.; Yu, K.; Kim, S.W.; Kwon, O.Y. Lidocaine induces endoplasmic reticulum stress-associated apoptosis in vitro and in vivo. Int. J. Mol. Sci. 2011, $12,7652-7661$.

27. Sirchia, S.M.; Ren, M.; Pili, R.; Sironi, E.; Somenzi, G.; Ghidoni, R.; Toma, S.; Nicolò, G.; Sacchi, N. Endogenous reactivation of the RARbeta2 tumor suppressor gene epigenetically silenced in breast cancer. Cancer Res. 2002, 62, 2455-2461.

28. Burbee, D.G.; Forgacs, E.; Zochbauer-Muller, S.; Shivakumar, L.; Fong, K.; Gao, B.; Randle, D.; Kondo, M.; Virmani, A.; Bader, S.; et al. Epigenetic inactivation of RASSF1A in lung and breast cancers and malignant phenotype suppression. J. Natl. Cancer Inst. 2011, 93, 691-699.

29. Agathanggelou, A.; Honorio, S.; Macartney, D.P.; Martinez, A.; Dallol, A.; Rader, J.; Fullwood, P.; Chauhan, A.; Walker, R.; Shaw, J.A.; et al. Methylation associated inactivation of RASSF1A from region 3p21.3 in lung, breast and ovarian tumours. Oncogene 2001, 20, 1509-1518.

30. Si, S.P.; Lee, X.; Tsou, H.C.; Buchsbaum, R.; Tibaduiza, E.; Peacocke, M. RAR beta 2-mediated growth inhibition in HeLa cells. Exp. Cell Res. 1996, 223, 102-111.

31. Swisshelm, K.; Ryan, K.; Lee, X.; Tsou, H.C.; Peacocke, M.; Sager, R. Down-regulation of retinoic acid receptor beta in mammary carcinoma cell lines and its up-regulation in senescing normal mammary epithelial cells. Cell Growth Differ. 1994, 5, 133-141.

32. Liu, Y.; Lee, M.O.; Wang, H.G.; Li, Y.; Hashimoto, Y.; Klaus, M.; Reed, J.C.; Zhang, X. Retinoic acid receptor beta mediates the growth-inhibitory effect of retinoic acid by promoting apoptosis in human breast cancer cells. Mol. Cell. Biol. 1996, 16, 1138-1149.

33. Rabizadeh, S.; Xavier, R.J.; Ishiguro, K.; Bernabeortiz, J.; Lopez-Ilasaca, M.; Khokhlatchev, A.; Mollahan, P.; Pfeifer, G.P.; Avruch, J.; Seed, B. The scaffold protein CNK1 interacts with the tumor suppressor RASSF1A and augments RASSF1A-induced cell death. J. Biol. Chem. 2004, 279, 29247-29254.

34. Ortiz-Vega, S.; Khokhlatchev, A.; Nedwidek, M.; Zhang, X.F.; Dammann, R.; Pfeifer, G.P.; Avruch, J. The putative tumor suppressor RASSF1A homodimerizes and heterodimerizes with the Ras-GTP binding protein Nore1. Oncogene 2002, 21, 1381-1390.

35. Song, M.S.; Song, S.J.; Kim, S.Y.; Oh, H.J.; Lim, D.S. The tumour suppressor RASSF1A promotes MDM2 self-ubiquitination by disrupting the MDM2-DAXX-HAUSP complex. EMBO J. 2008, 27, 1863-1874.

36. Liu, L.; Vo, A.; McKeehan, W.L. Specificity of the methylation-suppressed A isoform of candidate tumor suppressor RASSF1 for microtubule hyperstabilization is determined by cell death inducer C19ORF5. Cancer Res. 2005, 65, 1830-1838. 
37. Vassilomanolakis, M.; Koumakis, G.; Barbounis, V.; Demiri, M.; Pateras, H.; Efremidis, A.P. Vinorelbine and cisplatin in metastatic breast cancer patients previously treated with anthracyclines. Ann. Oncol. 2000, 11, 1155-1160.

38. Nole, F.; Munzone, E.; Mandala, M.; Catania, C.; Orlando, L.; Zampino, M.G.; Minchella, I.; Colleoni, M.; Peruzzotti, G.; Marrocco, E.; et al. Vinorelbine, cisplatin and continuous infusion of 5-fluorouracil (ViFuP) in metastatic breast cancer patients: A phase II study. Ann. Oncol. 2001, 12, 95-100.

39. Dixit, M.; Yang, J.L.; Poirier, M.C.; Price, J.O.; Andrews, P.A.; Arteaga, C.L. Abrogation of cisplatin-induced programmed cell death in human breast cancer cells by epidermal growth factor antisense RNA. J. Natl. Cancer Inst. 1997, 89, 365-373.

40. Sakakura, C.; Sweeney, E.A.; Shirahama, T.; Igarashi, Y.; Hakomori, S.; Tsujimoto, H.; Imanishi, T.; Ogaki, M.; Ohyama, T.; Yamazaki, J.; et al. Overexpression of bax sensitizes breast cancer MCF-7 cells to cisplatin and etoposide. Surg. Today 1997, 27, 676-679.

41. Blanc, C.; Deveraux, Q.L.; Krajewski, S.; Janicke, R.U.; Porter, A.G.; Reed, J.C.; Jaggi, R.; Marti, A. Caspase-3 is essential for procaspase-9 processing and cisplatin-induced apoptosis of MCF-7 breast cancer cells. Cancer Res. 2000, 60, 4386-4390.

42. Thomadaki, H.; Scorilas, A. Breast cancer cells response to the antineoplastic agents cisplatin, carboplatin, and doxorubicin at the mRNA expression levels of distinct apoptosis-related genes, including the new member, BCL2L12. Ann. N. Y. Acad. Sci. 2007, 1095, 35-44.

43. Yang, M.; Yuan, F.; Li, P.; Chen, Z.; Chen, A.; Li, S.; Hu, C. Interferon regulatory factor 4 binding protein is a novel p53 target gene and suppresses cisplatin-induced apoptosis of breast cancer cells. Mol. Cancer 2012, 11, 54.

44. Shiu, L.Y.; Chang, L.C.; Liang, C.H.; Huang, Y.S.; Sheu, H.M.; Kuo, K.W. Solamargine induces apoptosis and sensitizes breast cancer cells to cisplatin. Food Chem. Toxicol. 2007, 45, 2155-2164.

45. Schneider, B.G.; Peek, R.J. Gastric cancer prevention by demethylation. Cancer Prev. Res. 2013, 6 , 253-256.

46. Majid, S.; Dar, A.A.; Saini, S.; Shahryari, V.; Arora, S.; Zaman, M.S.; Chang, I.; Yamamura, S.; Tanaka, Y; Chiyomaru, T. miRNA-34b inhibits prostate cancer through demethylation, active chromatin modifications, and AKT pathways. Clin. Cancer Res. 2013, 19, 73-84.

47. Shin, H.; Kim, J.H.; Lee, Y.S.; Lee, Y.C. Change in gene expression profiles of secreted frizzled-related proteins (SFRPs) by sodium butyrate in gastric cancers: Induction of promoter demethylation and histone modification causing inhibition of Wnt signaling. Int. J. Oncol. 2012, 40, $1533-1542$.

48. Liu, J.; Xie, Y.S.; Wang, F.L.; Zhang, L.J.; Zhang, Y.; Luo, H.S. Cytotoxicity of 5-aza-2'-deoxycytidine against gastric cancer involves DNA damage in an ATM-P53 dependent signaling pathway and demethylation of P16(INK4A). Biomed. Pharmacother. 2013, 67, 78-87.

49. Singh, K.P.; Treas, J.; Tyagi, T.; Gao, W. DNA demethylation by 5-aza-2-deoxycytidine treatment abrogates 17 beta-estradiol-induced cell growth and restores expression of DNA repair genes in human breast cancer cells. Cancer Lett. 2012, 316, 62-69.

50. Seewaldt, V.L.; Johnson, B.S.; Parker, M.B.; Collins, S.J.; Swisshelm, K. Expression of retinoic acid receptor beta mediates retinoic acid-induced growth arrest and apoptosis in breast cancer cells. Cell Growth Differ. 1995, 6, 1077-1088. 
51. Levesley, J.; Lusher, M.E.; Lindsey, J.C.; Clifford, S.C.; Grundy, R.; Coyle, B. RASSF1A and the BH3-only mimetic ABT-737 promote apoptosis in pediatric medulloblastoma cell lines. Neuro Oncol. 2011, 13, 1265-1276.

52. Yi, M.; Yang, J.; Chen, X.; Li, J.; Li, X.; Wang, L.; Tan, Y.; Xiong, W.; Zhou, M.; McCarthy, J.B.; et al. RASSF1A suppresses melanoma development by modulating apoptosis and cell-cycle progression. J. Cell Physiol. 2011, 226, 2360-2369.

53. Matallanas, D.; Romano, D.; Yee, K.; Meissl, K.; Kucerova, L.; Piazzolla, D.; Baccarini, M.; Vass, J.K.; Kolch, W.; O’Neill, E. RASSF1A elicits apoptosis through an MST2 pathway directing proapoptotic transcription by the p73 tumor suppressor protein. Mol. Cell 2007, 27, 962-975.

54. Dammann, R.; Yang, G.; Pfeifer, G.P. Hypermethylation of the cpG island of Ras association domain family 1A (RASSF1A), a putative tumor suppressor gene from the $3 \mathrm{p} 21.3$ locus, occurs in a large percentage of human breast cancers. Cancer Res. 2011, 61, 3105-3109.

55. Niknafs, B. Induction of apoptosis and non-apoptosis in human breast cancer cell line (MCF-7) by cisplatin and caffeine. Iran. Biomed. J. 2011, 15, 130-133.

56. Mir, R.; Tortosa, A.; Martinez-Soler, F.; Vidal, A.; Condom, E.; Perez-Perarnau, A.; Ruiz-Larroya, T.; Gil, J.; Giménez-Bonafé, P. Mdm2 antagonists induce apoptosis and synergize with cisplatin overcoming chemoresistance in TP53 wild-type ovarian cancer cells. Int. J. Cancer 2013, 132, $1525-1536$.

57. Chu, F.; Barkinge, J.; Hawkins, S.; Gudi, R.; Salgia, R.; Kanteti, P.V. Expression of Siva-1 protein or its putative amphipathic helical region enhances cisplatin-induced apoptosis in breast cancer cells: Effect of elevated levels of BCL-2. Cancer Res. 2005, 65, 5301-5309.

58. Yoshida, Y.; Hosokawa, K.; Dantes, A.; Tajima, K.; Kotsuji, F.; Amsterdam, A. Theophylline and cisplatin synergize in down regulation of BCL-2 induction of apoptosis in human granulosa cells transformed by a mutated p53 (p53 val135) and Ha-ras oncogene. Int. J. Oncol. 2000, 17, 227-235.

59. Cho, N.Y.; Kim, B.H.; Choi, M.; Yoo, E.J.; Moon, K.C.; Cho, Y.M.; Kim, D.; Kang, G.H. Hypermethylation of CpG island loci and hypomethylation of LINE-1 and Alu repeats in prostate adenocarcinoma and their relationship to clinicopathological features. J. Pathol. 2007, 211, 269-277.

60. Eads, C.A.; Danenberg, K.D.; Kawakami, K.; Saltz, L.B.; Blake, C.; Shibata, D.; Danenberg, P.V.; Laird, P.W. MethyLight: A high-throughput assay to measure DNA methylation. Nucleic Acids Res. 2000, 28, E32.

61. Farias, E.F; Arapshian, A.; Bleiweiss, I.J.; Waxman, S.; Zelent, A.; Mira-Y-Lopez, R. Retinoic acid receptor alpha2 is a growth suppressor epigenetically silenced in MCF-7 human breast cancer cells. Cell Growth Differ. 2002, 13, 335-341.

62. Yan, P.S.; Shi, H.; Rahmatpanah, F.; Hsiau, T.H.; Hsiau, A.H.; Leu, Y.W.; Liu, J.C.; Huang, T.H. Differential distribution of DNA methylation within the RASSF1A CpG island in breast cancer. Cancer Res. 2003, 63, 6178-6186.

63. Livak, K.J.; Schmittgen, T.D. Analysis of relative gene expression data using real-time quantitative PCR and the 2(-Delta Delta C(T)) Method. Methods 2001, 25, 402-408.

(C) 2014 by the authors; licensee MDPI, Basel, Switzerland. This article is an open access article distributed under the terms and conditions of the Creative Commons Attribution license (http://creativecommons.org/licenses/by/4.0/). 